\title{
Insulin Resistance and Contrainsular Response in Type 2 Diabetes Mellitus Patients with Acute Coronary Syndrome
}

\author{
Dinara N. Sheryazdanova ${ }^{1 *}$, Yelena M. Laryushina ${ }^{1}$, Larissa Ye. Muravlyova ${ }^{2}$, Lyudmila G. Turgunova ${ }^{1}$, Assel R. Alina $^{1}$, \\ Natalya V. Vassilyeva ${ }^{1}$, Anar A. Turmukhambetova ${ }^{3}$
}

${ }^{1}$ Department of Internal Medicine 2, Karaganda Medical University, Karaganda, Kazakhstan; ${ }^{2}$ Department of Biological Chemistry, Karaganda Medical University, Karaganda, Kazakhstan; ${ }^{3}$ Department of Strategic Development, Karaganda Medical University, Research and International Collaboration, Karaganda, Kazakhstan

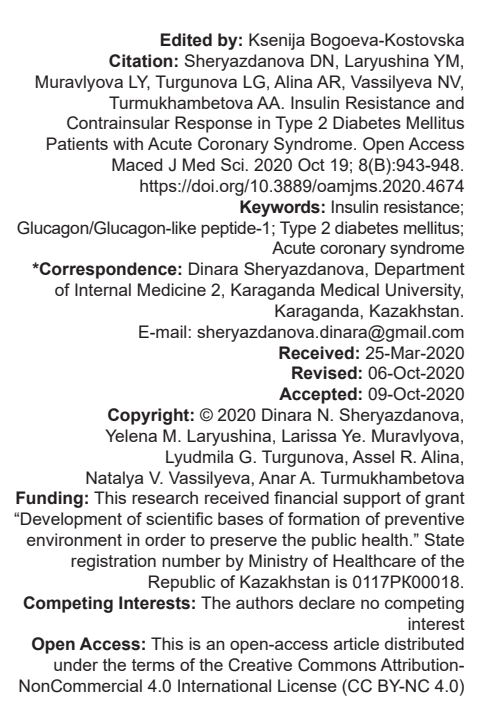

(

Mellitus th Acute Coronary Syndrome. Open Access (a)d J Med Sci. 2020 Oct 19; 8(B):943-948. (1) Type 2 diabetes mellitus yazdanova, Departmen araganda, Kazakhstan veceined: 25-Mar-2020 Revised: 06-Oct-2020 M. Laryushina, Larissa Ye. Muravlyova, unding: This research received financial support of grant nvironment in order to preserve the public health." State number by Ministry of Healthcare of the ompeting Interests: The authors declare no competing onCommercial 4 International License (CC BY-NC 4.0)

\begin{abstract}
BACKGROUND: The number of patients with diabetes mellitus (DM) is progressively increasing all over the world. Over the past three decades, the global burden of diabetes has increased from 30 million in 1985 to 382 million in 2015 , and current trends indicate that the prevalence of diabetes grows progressively. The phenomenon of insulin resistance established in the majority of type 2 DM (T2DM) patients. T2DM is associated with $\beta$-cell deficiency, $\alpha$-cell resistance to insulin, and reduced effects of incretin. However, the role of insulin and glucagon in the process of cardiovascular complications in diabetic patients is a matter of debate.
\end{abstract}

AIM: Our study aims to estimate insulin resistance and the contrainsular response in patients with T2DM and acute coronary syndrome (ACS).

METHODS: The 104 T2DM patients aged 18-70 years participated in the observational study carried out in the Karaganda regional cardiosurgery hospital and ambulatory. The first group included 37 patients hospitalized for ACS in the first $24 \mathrm{~h}$ of admission. The second group included 67 patients without ACS. Determination of insulin resistance and contrainsular response was provided using a multiplex immunological assay with XMap technology on Bioplex 3D.

RESULTS: During the research, we have discovered a decreased level of glucagon and increased homeostasis model assessment of insulin resistance (HOMA-IR) in patients with T2DM diabetes and ACS. Evaluation of traditiona correlation interactions of HOMA-IR and indicators of carbohydrate metabolism showed a positive correlation with fasting plasma glucose in both study groups (Group 1: $R=0.47, p=0.003$; Group 2: $R=0.41, p=0.024$ ). Glucagonlike peptide (GLP)-1 has a weak positive correlation with HOMA-IR only in the first group $(R=0.32, p=0.006)$. Increased insulin resistance was associated with high GLP-1 levels and low glucagon. The logistic regression mode established that an increased HOMA-IR index rises the chance of ACS by $10.6 \%$ (OR $=1.106[95 \% \mathrm{Cl} 1.105-1.206]$ $p=0,021)$. The logistic regression model, reflecting the relation between glucagon and ACS, shows that increased glucagon reduces the ACS odds (OR $=0.989$ [95\% Cl 0.979-0.999], $p=0.026)$. The adjusted regression mode showed no significant influence of early presented factors on the probability of ACS.

CONCLUSION: There is a trend toward elevated HOMA-IR insulin resistance index and decreased level of glucagon in diabetic patients with ACS.

\section{Introduction}

About $32.2 \%$ of all patients with type 2 diabetes mellitus (T2DM) around the world have cardiovascular diseases. Coronary artery disease and ischemic stroke cause approximately half of all deaths among people with diabetes [1].

The connection between T2DM and cardiovascular disease is undiscussable. Diabetes is considered one of the major independent cardiovascular risk factors, independent of additional confounders such as age, arterial hypertension, smoking, hypercholesterolemia, and left ventricular hypertrophy [2]. The mortality rate in patients with T2DM from macrovascular complications allows the researchers to think about its decisive importance for the further prognosis of the disease [3].
The fundamental pathogenetic role of hyperinsulinism in T2DM is established in many longitudinal studies [4], [5]. Insulin resistance criteria homeostasis model assessment of insulin resistance (HOMA-IR) associated with high cardiovascular risk have been shown in several studies [6], [8]. Increased insulin concentration elevates the risk of adverse cardiovascular outcomes in adult patients after coronary revascularization [9], [10]. However, the diagnostic significance of the quantitative assay of insulin resistance was insufficiently studied in T2DM and adverse cardiovascular events.

The simplest criteria of insulin resistance are HOMA-IR [11], [12], [13]. The association of HOMA-IR with a high cardiovascular risk is established in some studies of patients without diabetes [14], [15]. Nevertheless, the crosslink of HOMA-IR with the level of cardiovascular risk among patients with established type 
2 diabetes is controversial. In the Verona Diabetes Study, the Veteran's Affairs Diabetes Trial, and the study of highdensity lipoprotein (HDL) in patients with percutaneous coronary intervention, HOMA-IR is associated with an increased risk of cardiovascular events [16], [17]. The opposite trend with no link between HOMA-IR and adverse cardiovascular events is described in a study of cardiovascular risks in the UK [18].

At the same time, biomarkers of the contrainsular response are considered valuable pathogenetic biomarkers of T2DM. One of the important agents of this group is glucagon. In addition to the contrainsular action, glucagon plays a significant role in maintaining heart and kidneys function. Moreover, in the medical practice of the previous years, glucagon has been therapeutically used to treat heart failure.

In physiological conditions, glucagon secretion is regulated by insulin and somatostatin, as the main paracrine/endocrine inhibitors. Many other agents such as glucose, incretins (glucagon-like peptide (GLP)1 , amylin, leptin, fatty acids, ketone bodies, glucosedependent insulinotropic peptide (GIP), amino acids as I-arginine, and leucine could regulate its secretion. Meyer et al. demonstrated that GLP-2 can also stimulate glucagon secretion [19], [20].

Pathogenetic molecular changes in T2DM could be schematically characterized by $\beta$-cell deficiency, $\alpha$-cell resistance to insulin, and reduced effects of incretins. B-cell deficiency develops gradually, due to partial loss of their mass and dysfunction under the influence of genetic background of glucotoxicity and lipotoxicity and the advanced products of enhanced glycation [21]. Presumably, hyperglycemia induces long-term, self-sustaining processes in the vessels which are associated with oxidative stress and chronic inflammation. They play an important role in the "metabolic memory" phenomenon and insulin resistance process, as well as in the diabetic macro and microvascular complications development [22], [23].

The aim of the study was to evaluate the indicators of insulin resistance including insulin and C-peptide, and contrainsular response including glucagon and GLP 1, GIP in patients with type 2 diabetes and cardiovascular events (acute coronary syndrome $[A C S])$.

\section{Materials and Methods}

\section{Study subjects}

We conducted an observational cohort study of 104 patients with type 2 diabetes, aged 18-70 years old. The inclusion criteria were preexisting T2DM, either with the ACS at the first $24 \mathrm{~h}$ from the initial symptoms of a cardiovasculareventordiabeticpatientswith cardiovascular risk factors: Arterial hypertension, abdominal obesity, and dyslipidemia without cardiovascular events in medical history. Exclusion criteria were pregnancy, severe mental, and oncological diseases.

The sample size was calculated by the Kelsey method using EPI info software for unmatched cohort studies with a two-sided confidence level of $95 \%$, power is $80 \%$, the ratio of unexposed to exposed cases is 2 . The presence of outcomes (ACS in diabetic patients) was taken from the previous studies. The minimum exposed cases are 35 and unexposed is 69. The time of data collection was from October 2017 to June 2018 at Karaganda regional cardiosurgery hospital and different ambulatories of Karaganda city, Kazakhstan.

\section{Data collection}

The study inclusion process was started with the procedure of gaining signed informed consent. In both study groups, medical history, clinical examination, anthropometry, arterial blood pressure, plasma glucose, lipid profile, and glycosylated hemoglobin ( $\mathrm{HbA} 1 \mathrm{c})$ were collected. Physical examination included blood pressure measurement according to principles of the World Health Organization using a mechanical tonometer (Microlife BP AG1-10) on both hands with at least 10 min rest preliminary period [24]. The lowest of three consecutive measurements were taken for future calculations. Bodyweight and height were measured using a digital stadiometer with scales (TBEC RS-232). The body mass index (BMI) was calculated as body weight divided on a square of height in meters $\left(\mathrm{kg} / \mathrm{m}^{2}\right)$. Waist circumference (WC) was measured with non-elastic measuring tape on the thinnest part of the corpus.

\section{Blood samples}

Blood glucose measurement was provided using a glucose meter (Accu-Chek Active). The diagnosis of T2DM was established on the $\mathrm{HbA} 1 \mathrm{c}$ level greater or equal $6.5 \%$ by the 1997 American Diabetes Association [25]. HbA1c concentration was established with the NycoCard test system from venous blood by reflectometry method using the NycoCard Reader II blood analyzer. All the parameters of lipid profile (total cholesterol [TC], low-density lipoprotein cholesterol [LDL cholesterol], HDL cholesterol [HDL cholesterol], and triglycerides [TGs]) were estimated in plasma by the method of selective precipitation with phosphotungstate and magnesium.

Plasma samples were stored at $-70^{\circ} \mathrm{C}$ for not more than 3 months. We used method of the magnetic bead-based multiplex immunoassay using XMap technology for detecting insulin, C-peptide, glucagon, GLP-1, and GIP. The standard Bio-Plex Pro Human Diabetes, 10-Plex Panel kit was used to determine the concentration of listed metabolites in accordance with "Overnight protocol" by the instruction of the manufacturer. The protocol consisted of three steps. The first step was 
the incubation of unknown, standard, and control samples with magnetic beads loaded with primary antibodies. The second step was the revelation using detecting antibodies and Streptavidin Phycoerythrin Conjugated. The third step of the protocol was fluorescence registration using Bioplex 3D equipment (Luminex software). All detected analytes with minimum detectable concentration have a coefficient of variation $<10 \%$.

\section{Statistical analysis}

We conducted the Kolmogorov-Smirnov test for verification of the normal distribution of data. The description of the quantitative data was carried out by the median and quartiles. The Mann-Whitney $U$-test or $t$ was used to compare two independent parameters. The association of insulin resistance and contrainsular response was evaluated using the Spearman correlation coefficient and the binary logistic regression model. We use age, gender, treatment, social, and demographic characteristics for adjusted risk calculation. Statistical analysis was provided on IBM SPSS Statistics software, ver. 22.0. Results were considered statistically significant at $p<0.05$.

\section{Results}

The participants' baseline characteristics are presented in Table 1. The first group included 37 patients with T2DM and ACS, the second group comprised 67 T2DM patients without ACS. In the first group, there is bias to male patients. The median age of patients in the first group was higher than the second. Significant differences are also found among patients by the educational level and marital status. The number of participants with graduate education is lower in the ACS group in comparison with participants without ACS. Comparison of marital status same as the duration of T2DM shows the almost equal percentage of participants in both groups.

Table 1: Baseline characteristics participants $(n=104)$

\begin{tabular}{|c|c|c|c|}
\hline Parameter & $\begin{array}{l}1^{\text {st }} \text { group (T2DM with } \\
\text { ACS), } n=37\end{array}$ & $\begin{array}{l}2^{\text {nd }} \text { group (T2DM } \\
\text { without ACS) } n=67\end{array}$ & $\mathrm{p}$ \\
\hline Age, years & $59.00(54.00,63.25)$ & $49.50(37.50,56.75)$ & 0.001 \\
\hline Male (42) & $24(64.8)$ & $16(23.9)$ & 0.012 \\
\hline Female (62) & $13(35.2)$ & 51 (76.1) & 0.017 \\
\hline Middle school course & $23(62.2)$ & $39(58.2)$ & 0.112 \\
\hline Graduate education & $14(37.8)$ & $28(41.8)$ & 0.019 \\
\hline Single & $14(37.8)$ & $15(22.4)$ & 0.889 \\
\hline Married & $23(62.2)$ & $52(77.6)$ & 0.013 \\
\hline Duration of T2DM, years & $5.00(2.00,15.25)$ & $6.00(3.00,12.50)$ & 0.960 \\
\hline
\end{tabular}

Clinical and laboratory findings are presented in Table 2. In the group of patients with T2DM and ACS, compared with the group without ACS, there is a significant increase of traditional cardiovascular risk factors such as systolic blood pressure, diastolic blood pressure, and increased LDL level.
Table 2: Clinical and laboratory findings

\begin{tabular}{|c|c|c|c|}
\hline BMI, $\mathrm{kg} / \mathrm{m}^{2}$ & $30.76(25.10,34.37)$ & $28.43(25.08,32.65)$ & 0.193 \\
\hline WC, $\mathrm{cm}$ & $96.00(92.00,103.00)$ & $91.00(80.00,107.25)$ & 0.286 \\
\hline SBP, mm of mercury & $130.00(120.00,150.00)$ & $120,00(110.00,130.00)$ & 0.027 \\
\hline DBP, mm of mercury & $80.00(80.00,90.00)$ & $80.00(70.00,80.00)$ & 0.008 \\
\hline LDL, mmol/l & $0.92(0.75,1.19)$ & $1.10(0.87,1.33)$ & 0.041 \\
\hline $\mathrm{HDL}, \mathrm{mmol} / \mathrm{l}$ & $4.51(3.20,5.27)$ & $3.96(3.12,4.40)$ & 0.176 \\
\hline TG, mmol/l & $1.39(0.77,1.73)$ & $1.22(0.68,1.85)$ & 0.550 \\
\hline C-peptide, $\mathrm{ng} / \mathrm{ml}$ & $1430.03(831.63,2641.85)$ & $1098.35(754.22,2436.73)$ & 0.715 \\
\hline GLP-1, ng/ml & $113.47(70.42,141.91)$ & $82.95(54.70,134.75)$ & 0.185 \\
\hline GIP, ng/ml & $252.26(130.92,670.85)$ & $233.50(126.84,398.20)$ & 0.226 \\
\hline Glucagon, ng/ml & $57.79(51.11,150.26)$ & $1377.77(418.10,6078.86)$ & $<0.001$ \\
\hline Insulin, mU/L & $14.96(5.87,26.27)$ & $7.29(4.20,20,59)$ & 0.077 \\
\hline HOMA-IR & $4.58(1.62,9.55)$ & $1.95(0.876,6,56)$ & 0.035 \\
\hline \multicolumn{4}{|l|}{ T2DM treatment } \\
\hline Metformin & $23(62.2)$ & $43(64.2)$ & 0.786 \\
\hline Sulfonylurea & $9(24.3)$ & $13(19.4)$ & 0.634 \\
\hline IDPP4 & $1(2.9)$ & $4(5.9)$ & 0.606 \\
\hline Insulin & $4(10.8)$ & $7(11.9)$ & 0.064 \\
\hline
\end{tabular}

Estimation of insulin resistance provided by HOMA-IR calculation revealed an increased level of this parameter in patients with T2DM and ACS. A similar trend was noted for glucagon levels. There are no differences found by the middle school course, BMI, WC, plasma glucose level, HbA1c, TC, LDL cholesterol, TG, C peptide, GIP, and insulin.

Patients received one of three oral hypoglycemic agents: Metformin, sulfonylurea, DPP4 inhibitors (dipeptidyl peptidase-4 inhibitors), or insulin. No significant differences were found in the number of patients by prescribed therapy.

Assessment of correlation (Table 3 ) between the level of insulin resistance and anthropometric indicators revealed a middle positive correlation between HOMA-IR and BMI $(R=0.65, p=<0.001)$. Similar upward trend revealed for the patients from the second group $(R=0.47, p=0.010)$. A significant positive correlation of HOMA-IR with WC was noted only for a group of patients with T2DM and ACS. In both studied groups, there is a significant correlation between HOMA-IR and weight. Stronger interaction was in patients with T2DM without ACS (first group: $R=0.32, p=0.006$; second group: $R=0.62, p \leq 0.001$ ). An assessment of traditional correlation interactions of HOMA-IR and carbohydrate indicators showed an average positive correlation with fasting plasma glucose in both groups studied (the first group: $R=0.47$, $p=0.003$; the second group: $R=0.41, p=0.024$ ) GLP-1 responsible for the contrainsular response has a weak positive correlation with HOMA-IR only in the group of patients with T2DM and ACS $(R=0.32$, $p=0.006)$. Increased insulin resistance is associated with an increased GLP-1 level and a decreased glucagon level.

Table 3: Correlation coefficients of HOMA-IR

\begin{tabular}{llllll}
\hline Parameter & \multicolumn{2}{l}{$1^{\text {st }}$ group (T2DM with ACS) } & & \multicolumn{2}{l}{$2^{\text {nd }}$ group (T2DM without ACS) } \\
\cline { 2 - 3 } & $\mathrm{R}$ & $\mathrm{P}$ & & $\mathrm{R}$ & $\mathrm{P}$ \\
\hline BMI & 0.65 & $<0.001$ & & 0.47 & 0.010 \\
Plasma glucose & 0.47 & 0.003 & & 0.41 & 0.024 \\
WC & -0.18 & 0.474 & & 0.49 & 0.002 \\
Weight & 0.32 & 0.036 & & 0.62 & 0.001 \\
HbA1c & 0.16 & 0.409 & & -0.08 & 0.661 \\
C-peptide & 0.01 & 0.964 & & 0.06 & 0.716 \\
GLP-1 & 0.294 & 0.007 & & 0.13 & 0.506 \\
Glucagon & -0.09 & 0.653 & & 0.11 & 0.506 \\
\hline WC: Waist circumference & & & & &
\end{tabular}


A binary logistic regression model that assesses the effect of insulin resistance (Table 4) revealed that an increased HOMA-IR index significantly enhances the chance of ACS by $10.6 \%$, OR $=1.106$ (95\% Cl 1.105-1.206).

Table 4: Model of binary logistic regression for HOMA-IR, glucagon, and adjusted regression model for HOMA-IR and glucagon

\begin{tabular}{|c|c|c|c|c|}
\hline \multirow[t]{2}{*}{ Parameter } & \multirow[t]{2}{*}{ Significance } & \multirow[t]{2}{*}{ Odds ratio } & \multicolumn{2}{|c|}{$95 \% \mathrm{Cl}$ for $\exp (\mathrm{B})$} \\
\hline & & & Lower & Upper \\
\hline \multicolumn{5}{|l|}{ Model 1} \\
\hline HOMA-IR & 0.021 & 1.106 & 1.015 & 1.206 \\
\hline \multicolumn{5}{|l|}{ Model 2} \\
\hline Glucagon & 0.026 & 0.989 & 0.979 & 0.999 \\
\hline \multicolumn{5}{|c|}{$\begin{array}{l}\text { Model } 3 \text { Model of binary logistic regression for HOMA-IR and glucagon adjusted for age, } \\
\text { gender, marital status, and treatment }\end{array}$} \\
\hline Glucagon & 0.539 & 1.000 & 1.000 & 1.001 \\
\hline Insulin & 0.614 & 0.999 & 0.997 & 1.002 \\
\hline HOMA-IR & 0.660 & 1.040 & 0.874 & 1.238 \\
\hline
\end{tabular}

The binary logistic regression model, representing the relationship of the glucagon level with the ACS odds, shows that increased glucagon concentration significantly reduces the chance of the ACS onset $(\mathrm{OR}=0.989$ [95\% Cl 0.979-0.999]).

The model of binary logistic regression adjusted for age, gender, education, marital status, and treatment does not reveal any significant impact of HOMA-IR and glucagon on the probability of ACS. However, such cofounders as male gender (OR $=52,779$ [95\% Cl 4.687-94.391]) and age (OR = 1.193 [95\% Cl 1.036-1.375]) increase the ACS odds. The graduate education $(\mathrm{OR}=0.012[95 \% \mathrm{Cl} 0.000-0.324]$ ) reduces the probability of ACS.

\section{Discussion}

We have obtained the unambiguous data reflect the negative effect of insulin resistance on cardiovascular safety in our study. The level of HOMA-IR in patients with DM was higher during the ACS period than in similar patients with diabetes without ACS. It is also associated with an increased chance of an adverse cardiovascular event. At the same time, an increased level of HOMA-IR and decreased level of glucagon established an impact on the odds ratio of ACS [26]. The obtained results can be explained by the studies of $\alpha$-cells insulin resistance in T2DM. A-cells can be resistant to the inhibitory action of insulin or other $\beta$-cell secretory products, such as zinc or $\gamma$-aminobutyric acid [27].

In our research, glucagon shows diagnostic value in ACS prognosis. Moreover, glucagon shows greater significance than HOMA-IR in constructing a combined prognostic model of logistic regression. The impact of glucagon can be explained by the modern conception of DM pathogenesis. Diabetes is characterized by fasting hyperglycemia and impaired glucose-induced suppression of glucagon in the postprandial state. This condition arises mainly due to $\beta$-cells apoptosis and bias of the $\beta / \alpha$-cells ratio to $\alpha$-cells. The condition contributes to decreased insulin to glucagon ratio. Furthermore, $\beta$-cells can dedifferentiate to pluripotent predecessor cells that can release glucagon and somatostatin, thereby further reducing the insulin/glucagon ratio [28]. In this context, it seems clear that glucagon, with a certain reserve of its secretion, plays a major role in the reduction of metabolic effects of exceeding insulin secretion [29]. Besides, T2DM is characterized by a reduced effect of incretins, which progresses with the duration of the disease. Although the effects of GLP-1 are relatively preserved, prolonged hyperglycemia is capable of gradually suppressing the contrainsular response, creating a vicious cycle [30], [31].

The results obtained in our study did not match the concept that higher glucose level leads to the increased probability of ACS. According to such iconic studies as UKPDS and VADT, the glucose reduction is associated with a lower number of cardiovascular events and mortality in type 2 diabetes [32], [33], [34]. The data from these studies suggest that the glucoselowering conception that predominates in modern diabetology required achieving the target $\mathrm{HbA} 1 \mathrm{c}$ level to reduce the risk of diabetic complications.

The number of patients who reached the target level of $\mathrm{HbA} 1 \mathrm{c}$ in the groups with type 2 diabetes and ACS and T2DM without ACS was not statistically different. Besides, patients with and without ACS did not have statistical differences in $\mathrm{HbA} 1 \mathrm{c}$ level. The data of our study can be supported by the results of such large projects as the prospective observational study of the Verona Diabetes Study, where the main independent predictor of death in patients with diabetes was not $\mathrm{HbA1c}$ level, but glycemic variability [35].

The TC level, despite the increased level in both study groups, is not associated with ACS in our study. This fact corresponds to the results of many other studies that do not show the effectiveness of TC reduction to prevent the myocardial infarction risk [36].

In our study, there were no significant differences in LDL levels found between study groups. This fact contradicts the widely accepted theory of atherogenesis. These results can be explained by the limitation of the study as a small sample. One explanation is that our study has a small sample size; therefore, it is limited in a score. Unlike hypercholesterolemia, the manifestation of dyslipidemia in the form of a decreased serum HDL is identified as a more significant factor associated with the onset of an ACS, which is also established in our study [37], [38]. The average HDL concentration in the T2DM patients without ACS corresponds to the recommended target value, while in the T2DM patients with ACS, the average HDL level is below the recommended level.

\section{Limitations}

This study has potential limitations. The effects estimated in these models are based on a cohort study 
with relatively small sample size. The sample, selected for this study, was specifically patients with wellcontrolled T2DM, thus the results may not be applicable for diabetic patients outside of this designation. Future prospective studies suggested to estimate insulin and glucagon secretion in a more detailed way.

\section{Conclusion}

The results of our study showed that there is a trend toward elevated HOMA-IR and decreased level of glucagon in diabetic patients with ACS. However, this trend does not show significant impact on the ACS development probability. HOMA-IR and glucagon are possibly present a potential role in cardiovascular events in patients with T2DM.

\section{Authors' Contributions}

Sh.D, Ye.L., L.M., and A.A. carried out the experiment and wrote the manuscript with support from L.T. and N.V. A.T. helped supervise the project. D.Sh., Ye.L., and A.T conceived the original idea. All authors discussed the results and contributed to the final manuscript.

\section{References}

1. Einarson TR, Acs A, Ludwig C, Panton UH. Prevalence of cardiovascular disease in Type 2 diabetes: A systematic literature review of scientific evidence from across the world in 2007-2017. Cardiovasc Diabetol. 2018;17(1):83. https://doi. org/10.1186/s12933-018-0728-6

\section{PMid:29884191}

2. Stamler J, Vaccaro O, Neaton JD, Wentworth D. Diabetes, other risk factors, and 12-yr cardiovascular mortality for men screened in the multiple risk factor intervention trial. Diabetes Care. 1993;16(2):434-44. https://doi.org/10.2337/diacare.16.2.434 PMid:8432214

3. Mazurek M, Kowalczyk J, Lenarczyk R, Zielinska T, Sedkowska A, Pruszkowska-Skrzep P, et al. The prognostic value of different glucose abnormalities in patients with acute myocardial infarction treated invasively. Cardiovasc Diabetol. 2012;11:78. https://doi.org/10.1186/1475-2840-11-78 PMid:22741568

4. Nishimura M, Tokoro T, Nishida M, Hashimoto T, Kobayashi $H$, Yamazaki $\mathrm{S}$, et al. Association of insulin resistance with de novo coronary stenosis after percutaneous coronary artery intervention in hemodialysis patients. Nephron Clin Pract. 2008;109(1):c9-17. https://doi.org/10.1159/000132391 PMid:18483462
5. Uetani $\mathrm{T}$, Amano $\mathrm{T}$, Harada $\mathrm{K}$, Kitagawa $\mathrm{K}$, Kunimura $\mathrm{A}$, Shimbo $\mathrm{Y}$, et al. Impact of insulin resistance on post-procedural myocardial injury and clinical outcomes in patients who underwent elective coronary interventions with drug-eluting stents. JACC Cardiovasc Interv. 2012;5(11):1159-67. https://doi. org/10.1016/j.jcin.2012.07.008

PMid:23174640

6. Tenenbaum A, Adler Y, Boyko V, Tenenbaum H, Fisman EZ, Tanne D, et al. Insulin resistance is associated with increased risk of major cardiovascular events in patients with preexisting coronary artery disease. Am Heart J. 2007;153(4):559-65. https://doi.org/10.1016/j.ahj.2007.01.008 PMid:17383294

7. Yanase M, Takatsu F, Tagawa T, Kato T, Arai K, Koyasu M, et al. Insulin resistance and fasting hyperinsulinemia are risk factors for new cardiovascular events in patients with prior coronary artery disease and normal glucose tolerance. Circ J. 2004;68(1):47-52. https://doi.org/10.1253/circj.68.47 PMid: 14695465

8. Hedblad B, Nilsson P, Engström G, Berglund G, Janzon L. Insulin resistance in non-diabetic subjects is associated with increased incidence of myocardial infarction and death. Diabet Med. 2002;19(6):470-5. https://doi. org/10.1046/j.1464-5491.2002.00719.x PMid:12060058

9. Iguchi T, Hasegawa T, Otsuka K, Matsumoto K, Yamazaki T, Nishimura S, et al. Insulin resistance is associated with coronary plaque vulnerability: Insight from optical coherence tomography analysis. Eur Heart J Cardiovasc Imaging. 2014;15(3):284-91. https://doi.org/10.1093/ehjci/jet158 PMid:24022065

10. An $X, Y u$ D, Zhang R, Zhu J, Du R, Shi $Y$, et al. Insulin resistance predicts progression of de novo atherosclerotic plaques in patients with coronary heart disease: A one-year follow-up study. Cardiovasc Diabetol. 2012;11:71. https://doi. org/10.1186/1475-2840-11-71 PMid:22709409

11. Okita K, Iwahashi H, Kozawa J, Okauchi $\mathrm{Y}$, Funahashi T, Imagawa $\mathrm{A}$, et al. Homeostasis model assessment of insulin resistance for evaluating insulin sensitivity in patients with Type 2 diabetes on insulin therapy. Endocr J. 2013;60(3):283-90. https://doi.org/10.1507/endocrj.ej12-0320

PMid:23149658

12. Bonora $\mathrm{E}$, Targher $\mathrm{G}$, Alberiche M, Bonadonna RC, Saggiani $\mathrm{F}$ Zenere $\mathrm{MB}$, et al. Homeostasis model assessment closely mirrors the glucose clamp technique in the assessment of insulin sensitivity: Studies in subjects with various degrees of glucose tolerance and insulin sensitivity. Diabetes Care. 2000;23(1):5763. https://doi.org/10.2337/diacare.23.1.57 PMid:10857969

13. Gruden G, Landi A, Bruno G. Natriuretic peptides, heart, and adipose tissue: New findings and future developments for diabetes research. Diabetes Care. 2014;37(11):2899-908. https://doi.org/10.2337/dc14-0669

PMid:25342830

14. Asztalos BF, Collins D, Cupples LA, Demissie S, Horvath KV, Bloomfield $\mathrm{HE}$, et al. Value of high-density lipoprotein (HDL) subpopulations in predicting recurrent cardiovascular events in the veterans affairs $\mathrm{HDL}$ intervention trial. Arterioscler Thromb Vasc Biol. 2005;25(10):2185-91. https://doi.org/10.1161/01. atv.0000183727.90611.4f PMid:16123324

15. Stähli BE, Nozza A, Schrieks IC, Buse JB, Malmberg K, Mellbin L, et al. Homeostasis model assessment of insulin resistance and survival in patients with diabetes and acute coronary syndrome. J Clin Endocrinol Metab. 
2018;103(7):2522-33. https://doi.org/10.1210/jc.2017-02772 PMid:29659887

16. Hippisley-Cox J, Coupland C. Development and validation of risk prediction equations to estimate future risk of heart failure in patients with diabetes: A prospective cohort study. BMJ Open. 2015;5(9):e008503. https://doi.org/10.1136/ bmjopen-2015-008503

PMid:26353872

17. Bonora E, Formentini G, Calcaterra F, Lombardi S, Marini F, Zenari L, et al. HOMA-estimated insulin resistance is an independent predictor of cardiovascular disease in Type 2 diabetic subjects: Prospective data from the Verona diabetes complications study. Diabetes Care. 2002;25(7):1135-41. https://doi.org/10.2337/diacare.25.7.1135

PMid: 12087010

18. Adler Al, Levy JC, Matthews DR, Stratton IM, Hines G, Holman RR. Insulin sensitivity at diagnosis of Type 2 diabetes is not associated with subsequent cardiovascular disease (UKPDS 67). Diabet Med. 2005;22(3):306-11. https://doi. org/10.1111/j.1464-5491.2004.01418.x PMid:15717879

19. Ahrén B. Glucagon--early breakthroughs and recent discoveries. Peptides. 2015;67:74-81. https://doi.org/10.1016/j. peptides.2015.03.011 PMid:25814364

20. Jones BJ, Tan T, Bloom SR. Minireview: Glucagon in stress and energy homeostasis. Endocrinology. 2012;153(3):1049-54. https://doi.org/10.1210/en.2011-1979 PMid:22294753

21. Cartañà J, Arola L. Nickel-induced hyperglycaemia: The role of insulin and glucagon. Toxicology. 1992;71(1-2):181-92. https:// doi.org/10.1016/0300-483x(92)90065-m PMid:1729765

22. Ceriello A. Oxidative stress and diabetes-associated complications. Endocr Pract. 2006;12 Suppl 1:60-2 PMid:16627383

23. Klimontov VV, Myakina NE. Glycaemic variability in diabetes: A tool for assessing the quality of glycaemic control and the risk of complications. J Diabetes Mellit. 2014;17(2):76-82. https://doi. org/10.14341/dm2014276-82

24. Summary of the 2007 European Society of Hypertension (ESH) and European Society of Cardiology (ESC) guidelines for the management of arterial hypertension. Vasc Health Risk Manag. 2007;3(6):783-95. https://doi.org/10.1080/08037050701461084 PMid:18200799

25. Expert Committee on the Diagnosis and Classification of Diabetes Mellitus. Report of the expert committee on the diagnosis and classification of diabetes mellitus. Diabetes Care. 2003;26 Suppl 1:S5-20. https://doi.org/10.2337/diacare.21.1.s5 PMid: 12502614

26. Yamagishi S, Fukami K, Matsui T. Crosstalk between advanced glycation end products (AGEs)-receptor RAGE axis and dipeptidyl peptidase-4-incretin system in diabetic vascular complications. Cardiovasc Diabetol. 2015;14:2. https://doi. org/10.1186/s12933-015-0176-5 PMid:25582643

27. Ali S, Drucker DJ. Benefits and limitations of reducing glucagon action for the treatment of Type 2 diabetes. Am J Physiol Endocrinol Metab. 2009;296(3):E415-21.

\section{PMid: 19116373}

28. Godoy-Matos AF. The role of glucagon on Type 2 diabetes at a glance. Diabetol Metab Syndr. 2014;6(1):91. https://doi. org/10.1186/1758-5996-6-91

PMid:25177371

29. Winnick JJ, Kraft G, Gregory JM, Edgerton DS, Williams P, Hajizadeh IA, et al. Hepatic glycogen can regulate hypoglycemic counterregulation via a liver-brain axis. J Clin Invest. 2016;126(6):2236-48. https://doi.org/10.1172/jci79895 PMid:27140398

30. Unger RH, Cherrington AD. Glucagonocentric restructuring of diabetes: A pathophysiologic and therapeutic makeover. J Clin Invest. 2012;122(1):4-12. https://doi.org/10.1172/jci60016 PMid:22214853

31. Norhammar A, Tenerz A, Nilsson G, Hamsten A, Efendíc S, Rydén $\mathrm{L}$, et al. Glucose metabolism in patients with acute myocardial infarction and no previous diagnosis of diabetes mellitus: A prospective study. Lancet. 2002;359(9324):2140-4. https://doi.org/10.1016/s0140-6736(02)09089-x

PMid:12090978

32. Hayward RA, Reaven PD, Wiitala WL, Bahn GD, Reda DJ, $\mathrm{Ge} \mathrm{L}$, et al. Follow-up of glycemic control and cardiovascular outcomes in Type 2 diabetes. N Engl J Med. 2015;372(23):2197206. https://doi.org/10.1056/nejmoa1414266 PMid:26039600

33. Nichols GA, Joshua-Gotlib S, Parasuraman S. Glycemic control and risk of cardiovascular disease hospitalization and all-cause mortality. J Am Coll Cardiol. 2013;62(2):121-7. https://doi. org/10.1016/j.jacc.2013.04.031 PMid:23665365

34. Muggeo M, Zoppini G, Bonora E, Brun E, Bonadonna RC, Moghetti $\mathrm{P}$, et al. Fasting plasma glucose variability predicts 10-year survival of Type 2 diabetic patients: The Verona diabetes study. Diabetes Care. 2000;23(1):45-50. https://doi. org/10.2337/diacare.23.1.45 PMid:10857967

35. Stratton IM, Adler AI, Neil HA, Matthews DR, Manley SE, Cull CA, et al. Association of glycaemia with macrovascular and microvascular complications of Type 2 diabetes (UKPDS 35): Prospective observational study. BMJ. 2000;321(7258):405-12. https://doi.org/10.1136/bmj.321.7258.405 PMid:10938048

36. Khan HA, Alhomida AS, Sobki SH. Lipid profile of patients with acute myocardial infarction and its correlation with systemic inflammation. Biomark Insights. 2013;8:1-7. https://doi. org/10.4137/bmi.s11015

PMid:23400110

37. Chinwong D, Patumanond J, Chinwong S, Siriwattana K, Gunaparn S, Hall JJ, et al. Statin therapy in patients with acute coronary syndrome: Low-density lipoprotein cholesterol goal attainment and effect of statin potency. Ther Clin Risk Manag. 2015;11:127-36. https://doi.org/10.2147/tcrm.s75608 PMid:25670902

38. Ozaki Y, Tanaka A, Nishiguchi T, Komukai K, Taruya A, Satogami K, et al. High-density lipoprotein cholesterol as a therapeutic target for residual risk in patients with acute coronary syndrome. PLoS One. 2018;13(7):e0200383. https:// doi.org/10.1371/journal.pone.0200383

PMid:29995934 